\title{
Synthesis of cuprous oxides thin film with different morphologies by electrodeposition
}

\author{
Lijuan Wan ${ }^{1,2^{*}}$, Dongxiang Cheng ${ }^{1,2}$ and Ping Wang ${ }^{1}$ \\ ${ }^{1}$ Nanjing Communications Institute of Technology, Nanjing 211188, China; \\ 2 Jiangsu Engineering Technology Research Center for Energy Conservation and Emission \\ Reduction of Transportation, Nanjing 211188, China. \\ *bartty_ym@163.com.
}

Keywords: Cuprous oxide; electrochemical growth; thin film.

\begin{abstract}
Cuprous oxides thin film with different morphologies were formed on F-doped tin oxide (FTO) covered glass substrates by potentiostatic deposition of cupric acetate. The effects of electrodeposition temperature and $\mathrm{Br}^{-}$on the crystal morphologies of cuprous oxide were studied. Different crystal morphologies of cuprous oxides were obtained by the change of electrodeposition temperature or the concentrations of $\mathrm{Br}^{-}$. The network-like and tetrahedron morphologies of $\mathrm{Cu}_{2} \mathrm{O}$ crystals were obtained when using higher deposition temperature and concentration of $\mathrm{KBr}$, respectively. Photoelectrochemical behavior of the cuprous oxides thin films prepared in the system was also studied.
\end{abstract}

\section{Introduction}

As a direct band-gap semiconductor, cuprous oxide $\left(\mathrm{Cu}_{2} \mathrm{O}\right)$ with its environmentally benign nature of copper and low cost is desirably used in many ways including catalysis [1], sensors [2] and energy conversion such as solar cells for both its relatively high light absorption coefficient in visible region $[3,4]$ and appropriate band gap $\left(E_{\mathrm{g}}=1.9 \sim 2.2 \mathrm{eV}\right)$. Recently, it has been documented that chemical and physical properties depend greatly on the microstructures, such as crystal size, orientation of inorganic nanomaterials [5], and morphological characters, e.g., the photoelectrochemical properties $\mathrm{Cu}_{2} \mathrm{O}$ have been greatly influenced by their morphologies [6]. Because the electronic structure, surface energy and chemical reactivities of micro- or nanomaterials are greatly related to their surface morphologies [5,7], the development of micro- or nanomaterials may open new opportunities for exploring the physical and chemical properties. The conduction band edge (ca. $-1.35 \mathrm{~V}$ vs. Ag/AgCl at $\mathrm{pH}=7$ ) and valence band edge (ca. $-0.61 \mathrm{~V}$ vs. $\mathrm{Ag} / \mathrm{AgCl}$ at $\mathrm{pH}=7$ ) of $\mathrm{Cu}_{2} \mathrm{O}$ are located near the reduction and oxidation potentials of water respectively, thus it is feasible to use $\mathrm{Cu}_{2} \mathrm{O}$ for hydrogen generation from visible light-induced photocatalytic water splitting [8,9].

Various methods such as electrodeposition route [10], wet chemistry method [11] and gas phase deposition techniques [12], have been developed for the synthesis of $\mathrm{Cu}_{2} \mathrm{O}$ with different microstructures. Among these methods, electrochemical deposition which presents a gentle, simple and economical method with the advantage of allowing patterned and controlled crystal growth has shown the advantage to control the crystallization engineering of large area $\mathrm{Cu}_{2} \mathrm{O}$ films.

There are two steps in the process of electrodeposition of $\mathrm{Cu}_{2} \mathrm{O}$. Reduction of $\mathrm{Cu}^{2+}$ ions to $\mathrm{Cu}^{+}$ ions is the first step (eq 1); Due to the solubility limitation of $\mathrm{Cu}^{+}$ions, precipitation of $\mathrm{Cu}^{+}$ions to $\mathrm{Cu}_{2} \mathrm{O}$ is the second step (eq 2) [13].

$$
\begin{aligned}
& \text { "Cu } \mathrm{Cu}^{2+}+\mathrm{e}^{-} \longleftrightarrow \mathrm{Cu}^{+} E^{\mathrm{o}}=0.159 \mathrm{~V} \\
& 2 \mathrm{Cu}^{+}+\mathrm{H}_{2} \mathrm{O} \longleftrightarrow \mathrm{Cu}_{2} \mathrm{O}+2 \mathrm{H}^{+} \log \left[\mathrm{Cu}^{+}\right]=0.84-\mathrm{pH} \\
& 2 \mathrm{Cu}^{2+}+\mathrm{H}_{2} \mathrm{O}+2 \mathrm{e}^{-} \longleftrightarrow \mathrm{Cu}_{2} \mathrm{O}+2 \mathrm{H}^{+} \text {(overall reaction)" }
\end{aligned}
$$

In previous studies, during the process of crystal growth of $\mathrm{Cu} 2 \mathrm{O}$ by electrodeposition, the influences of anion, cation or surfactant on the growth of cuprous oxide such as NH4+ [14], SDS [15], have been explored and it has been reported that $\mathrm{Cl}$ - ions are preferentially adsorbed on $\{100\}$ planes and sodium dodecyl sulfate ions on $\{111\}$. Generally, in electrodeposition process, the dendritic branching growth can be induced when deposition rate is increased to form depletion zone of nutrient 
ions (i.e., $\mathrm{Cu} 2+$ for $\mathrm{Cu} 2 \mathrm{O}$ deposition) around a growing crystal [6]. However, in cupric acetate system, the influences of $\mathrm{Br}$ - on the crystal growth of $\mathrm{Cu} 2 \mathrm{O}$ have been rarely studied with continuous concentrations during electrodeposition process. Usually, $\mathrm{Cu} 2 \mathrm{O}$ is prepared as a p-type material, while only a handful of synthesis method such as electrodeposition have been reported to prepare n-type Cu2O [16], which may be beneficial to build photoelectrochemical cells based on a p-n Cu2O homojunction [17]. In this study, the influences of deposition temperature and $\mathrm{Br}$ - on the crystal morphology of cuprous oxide were investigated in the process of electrodeposition, and the photoelectrochemical properties of the samples were also investigated.

\section{Experimental Section}

\subsection{Preparation of $\mathrm{Cu}_{2} \mathrm{O}$ film}

Synthesis of $\mathrm{Cu} 2 \mathrm{O}$ thin film was carried out in a glass cell equipped with a $15 \times 20 \mathrm{~mm} 2$ platinum plate as the counter electrode and a saturated calomel electrode as the reference electrode at different temperatures. The working electrode was a FTO glass with a surface area of $15 \times 10 \mathrm{~mm} 2$ exposed to the electrolyte. The electrolytes are $0.02 \mathrm{M} \mathrm{Cu}(\mathrm{Ac}) 2$ and $0.1 \mathrm{M} \mathrm{NaAc}$ aqueous solution and added with different concentrations of $\mathrm{KBr}$. The $\mathrm{pH}$ values of electrolytes were 5.75 by adding acetic acid. The FTO glass electrode was carefully washed with acetone and distilled water before experiments. $\mathrm{Cu} 2 \mathrm{O}$ thin films were prepared through the electrodeposition route in a potentiostatic mode using a commercial electrochemical workstation (CHI633C, China). It is practiced at $\mathrm{E}=-0.2 \mathrm{~V}$.

\subsection{Characterization}

The as-prepared samples were characterized by X-ray diffraction (XRD) for phase identification on a Rigaku D/MAX-Ultima III X-ray diffractometer with $\mathrm{Cu} \mathrm{K} \alpha$ radiation $(\lambda=0.154 \mathrm{~nm}, 40 \mathrm{kV}, 40$ $\mathrm{mA}$, a scan rate of $\left.10^{\circ} \cdot \mathrm{min}-1\right)$. The microstructure of deposited particles was characterized by scanning electron microscopy (SEM, Philips XL30) with an electron accelerating voltage of $10 \mathrm{kV}$. With 500W xenon lamp (USHIO Optical Module X500) illumination, the photoelectrochemical properties were characterized by linear scanning voltampere (LSV) technique from -0.20 to $0.05 \mathrm{~V}$ with a scan rate of $0.02 \mathrm{~V} / \mathrm{s}$ performed on a electrochemical workstation (CHI633C). The solutions were purged of $\mathrm{O} 2$ through the bubbling of $\mathrm{N} 2$ for at least 60 min before the measurements. The LSV measurements were performed in a $0.02 \mathrm{M} \mathrm{K2SO} 4$ aqueous solution in a standard three-electrode configuration coupled with the as-prepared sample film (working electrode), a high purity platinum (counter electrode) and an $\mathrm{Ag} / \mathrm{AgCl}$ electrode (reference electrode).

\section{Results and Discussion}

The representative XRD pattern of as-deposited Cu2O film on the FTO-glass substrate using the electrolyte containing $0.02 \mathrm{M}$ copper acetate, $0.1 \mathrm{M}$ sodium acetate at room temperature is shown in Fig. 1. According to JCPDS card No. 65-3288, the XRD result indicate that the crystallographic phase of the as-deposited film could be indexed to $\mathrm{Cu} 2 \mathrm{O}$ with the cubic structure (Pn-3m). There are no other peaks observed in the XRD result except for the diffraction peaks of $\mathrm{Cu} 2 \mathrm{O}$ and FTO-glass, which means single-phase $\mathrm{Cu} 2 \mathrm{O}$ can be obtained route in this system through electrodeposition. 


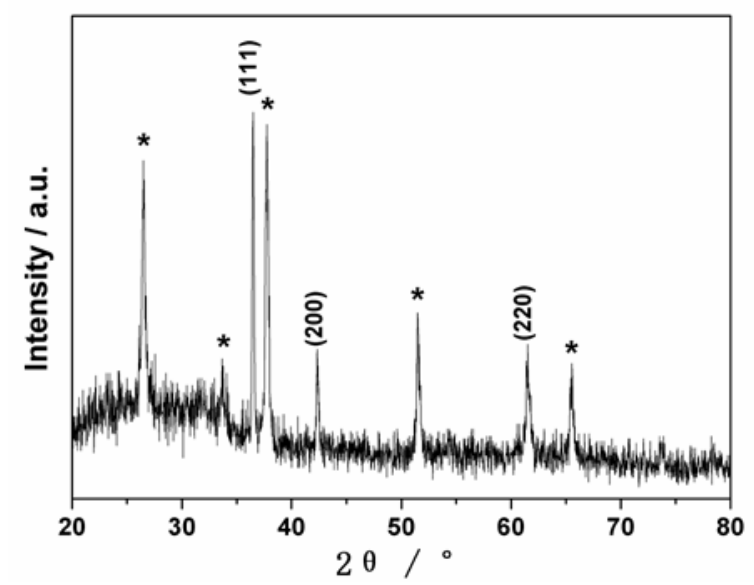

Fig. $1 \mathrm{XRD}$ pattern of $\mathrm{Cu} 2 \mathrm{O}$ thin film deposited in $0.02 \mathrm{M}$ copper acetate, $0.1 \mathrm{M}$ sodium acetate at room temperature; The label $\left(^{*}\right)$ represents the diffraction peaks from FTO-substrate (JCPDS card no. 41-1445).

Fig. 2 shows the SEM images of $\mathrm{Cu} 2 \mathrm{O}$ crystals deposited at $\mathrm{E}=-0.2 \mathrm{~V}$ for 20 min in solutions containing $0.02 \mathrm{M}$ copper acetate, $0.1 \mathrm{M}$ sodium acetate at different temperatures. The results show obvious change in $\mathrm{Cu} 2 \mathrm{O}$ crystal morphologies with the increase of temperature. From Fig. 2a and b, the low- and high-magnification SEM images show the $\mathrm{Cu} 2 \mathrm{O}$ film prepared at room temperature has compact and uniform structure. From Fig. 2c and d, Cu2O with dendric morphology is deposited when the temperature was increased to $40{ }^{\circ} \mathrm{C}$. From Fig. 2e and $\mathrm{f}$, the network-like Cu2O appears when the temperature was increased to $70{ }^{\circ} \mathrm{C}$. Based on these results, the temperature of the electrodeposition system is supposed to play a key role in controlling the morphologies of the as-prepared $\mathrm{Cu} 2 \mathrm{O}$ films.

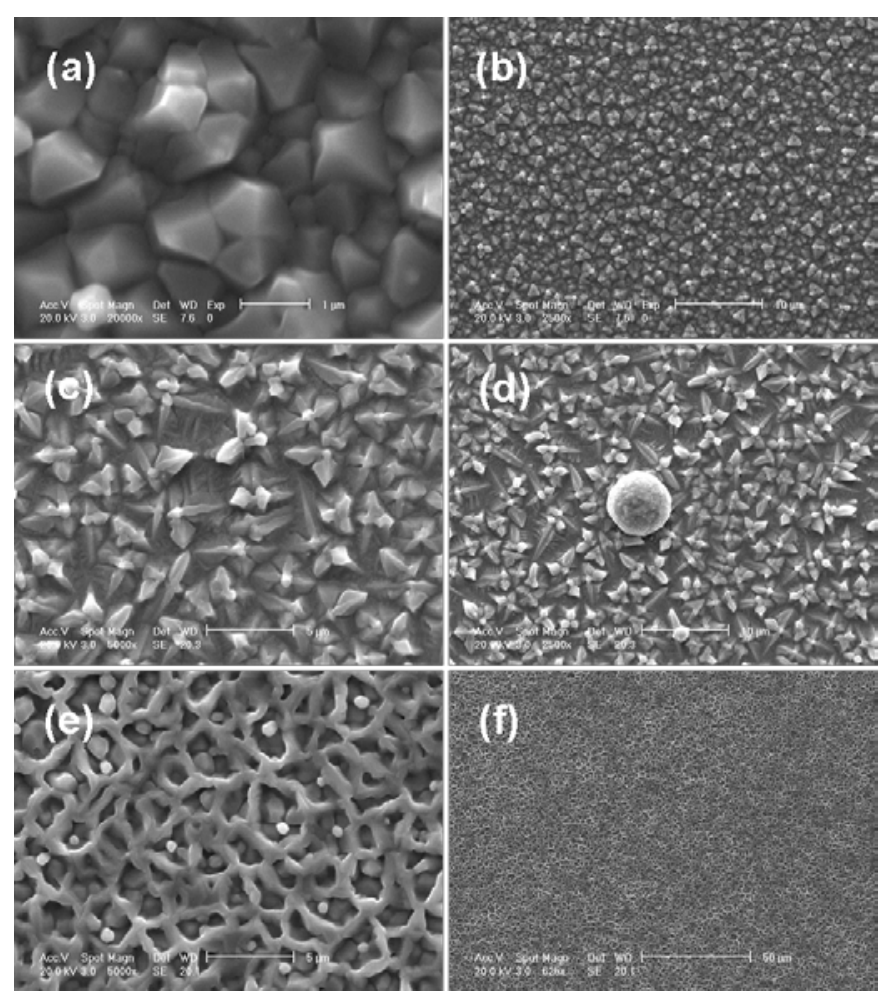

Fig. 2 Low- and high-magnification SEM images of Cu2O deposited for $20 \mathrm{~min}$ in the electrolyte containing $0.02 \mathrm{M}$ copper acetate, $0.1 \mathrm{M}$ sodium acetate and different temperatures: (a,b) room temperature; (c,d) $40{ }^{\circ} \mathrm{C}$; (e,f) $70{ }^{\circ} \mathrm{C}$. 
The SEM images of the products deposited in the electrolyte composed of $\mathrm{NaAc}$ and $\mathrm{Cu}(\mathrm{Ac}) 2$ with different concentrations of $\mathrm{KBr}$ are shown in Fig. 3. From Fig. 3, the observed morphology of $\mathrm{Cu} 2 \mathrm{O}$ particles was changed from polyhedron-like shape to tetrahedron-like shape with increasing the concentration of $\mathrm{KBr}$. With adding less $\mathrm{KBr}$, the polyhedron-like structure was shaped (Fig. 3a, b). With the increase of the concentration of $\mathrm{KBr}$, tetrahedron-like shape appeared (Fig. 3c, d). The results indicated that, in addition to the reactants, the morphology of the $\mathrm{Cu} 2 \mathrm{O}$ films highly depended on the concentration of $\mathrm{KBr}$ in electrolyte. Thus, the formation mechanism of $\mathrm{Cu} 2 \mathrm{O}$ morphological changes might be attributed to the adsorption of $\mathrm{Br}$ - ions on some planes, which in turn changed the surface energies and hindered the crystal growth of some planes, resulting in the changes of the $\mathrm{Cu} 2 \mathrm{O}$ crystal morphology.

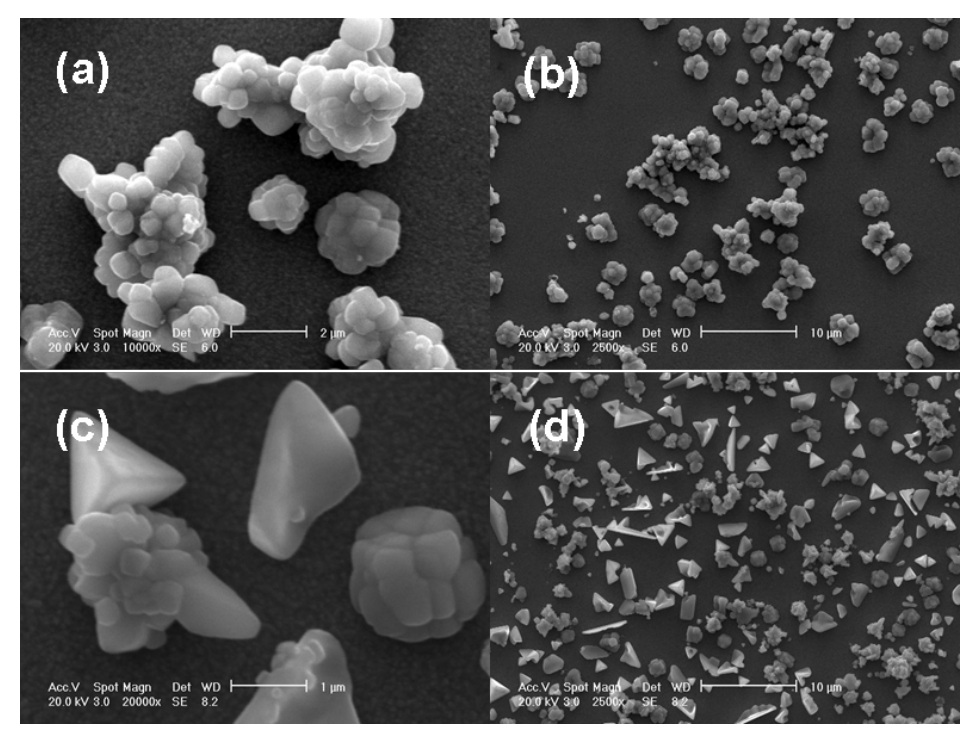

Fig. 3 Low- and high-magnification SEM images of $\mathrm{Cu} 2 \mathrm{O}$ deposited for $5 \mathrm{~min}$ in the electrolyte containing 0.02 M copper acetate, $0.1 \mathrm{M}$ sodium acetate and different concentrations of $\mathrm{KBr}$ : (a,b) 1.5 $\mathrm{mM}$; (c,d) $3.0 \mathrm{mM}$ at room temperature.

Taking $\mathrm{Cu} 2 \mathrm{O}$ film deposited in the electrolyte at room temperature as the example, the photo-electrochemical properties of the as-deposited $\mathrm{Cu} 2 \mathrm{O}$ films were studied and the result is shown in Fig. 4. From Fig. 4, it is clearly shown that the as-deposited $\mathrm{Cu} 2 \mathrm{O}$ film can produce anodic photocurrent, which indicates that $\mathrm{Cu} 2 \mathrm{O}$ prepared by electrodeposition in this system is n-type semiconductor photoelectrode [6] and it is possible to form p-n homojunction with p-Cu2O.

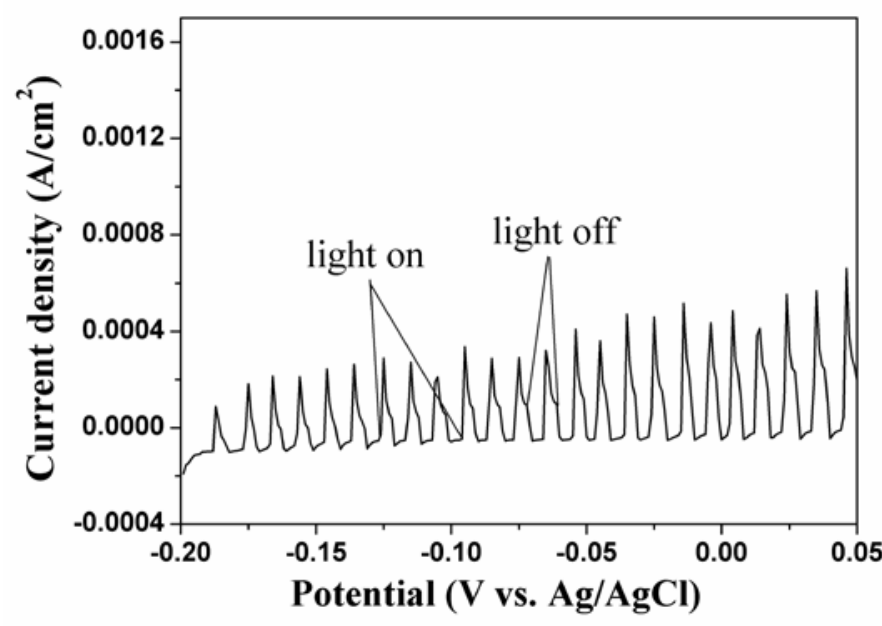

Fig. 4 Photocurrent curve from -0.2 to $0.05 \mathrm{~V}$ for $\mathrm{Cu}_{2} \mathrm{O}$ films deposited for $20 \mathrm{~min}$ at room temperature. 


\section{Conclusions}

In summary, crystal morphologies of $\mathrm{Cu} 2 \mathrm{O}$ by electrodeposition can be modulated in cupric acetate system with different concentrations of $\mathrm{Br}$ - or temperature. With the increase of deposition temperature, the morphologies of $\mathrm{Cu} 2 \mathrm{O}$ change from compact, dendric to network-like shapes. $\mathrm{Br}$ shows great influence on the microstructure of $\mathrm{Cu} 2 \mathrm{O}$. $\mathrm{Cu} 2 \mathrm{O}$ tetrahedron-like crystals appear when the concentration of $\mathrm{KBr}$ increases. $\mathrm{Cu} 2 \mathrm{O}$ prepared in this electroposition system is n-type semiconductor photoelectrode, which may be useful by forming p-n homoconjunction with p-Cu2O in various fields such as solar cells.

\section{Acknowledgement}

This work was supported by a grant from Scientific Research Project of Nanjing Communications Institute of Technology (JY1304), High-level Scientific Research Foundation for the introduction of talent of Nanjing Communications Institute of Technology and Qing Lan Project of Nanjing Communications Institute of Technology.

\section{References}

[1] J. Ramirez-Ortiz, T. Ogura, J. Medina-Valtierra, S. E. Acosta-Ortiz, P. Bosch, J. A. De Los Reyes, V. H. Lara, A catalytic application of $\mathrm{Cu}_{2} \mathrm{O}$ and $\mathrm{CuO}$ films deposited over fiberglass, Appl. Surf. Sci. 174 (2001) 177-184.

[2] J. Li, H. B. Li, Y. Xue, H. L. Fang, W. Wang, Facile electrodeposition of environment-friendly $\mathrm{Cu}_{2} \mathrm{O} / \mathrm{ZnO}$ heterojunction for robust photoelectrochemical biosensing, Sensors and Actuators B 191 (2014) 619- 624.

[3] K. Akimoto, S. Ishizuka, M. Yanagita, Y. Nawa, G. K. Paul, T. Sakuri, Thin film deposition of $\mathrm{Cu}_{2} \mathrm{O}$ and application for solar cells, Sol. Energy 80 (2006) 715-722.

[4] M. Izaki, T. Shinagawa, K. -T. Mizuno, Y. Ida, M. Inaba, A. Tasaka, Electrochemically constructed $\mathrm{p}-\mathrm{Cu}_{2} \mathrm{O} / \mathrm{n}-\mathrm{ZnO}$ heterojunction diode for photovoltaic device, J. Phys. D: Appl. Phys. 40 (2007) 3326-3329.

[5] J. G. Yu, X. X. Yu, Hydrothermal synthesis and photocatalytic activity of zinc oxide hollow spheres, Environ. Sci. Technol. 2008, 42 (13): 4902-4907.

[6] C. M. McShane, K. -S. Choi, Photocurrent enhancement of n-type $\mathrm{Cu}_{2} \mathrm{O}$ electrodes achieved by controlling dendritic branching growth, J. Am. Chem. Soc. 131 (2009) 2561-2569.

[7] W. Zhu, X. Feng, L. Feng, L. Jiang, UV-Manipulated wettability between superhydrophobicity and superhydrophilicity on a transparent and conductive $\mathrm{SnO}_{2}$ nanorod film, Chem. Commun. (2006) 2753-2755.

[8] P. E. de Jongh, D. Vanmaekelbergh, J. J. Kelly, $\mathrm{Cu}_{2} \mathrm{O}$ : a catalyst for the photochemical decomposition of water? Chem. Commun. (1999) 1069-1070.

[9] J. -N. Nian, C. -C. Hu, H. Teng, Electrodeposited p-type $\mathrm{Cu}_{2} \mathrm{O}$ for $\mathrm{H}_{2}$ evolution from photoelectrolysis of water under visible light illumination, Int. J. Hydrogen Energy 33 (2008) 2897-2903.

[10] J. B. Xue, Q. Q. Shen, W. Liang, X. G. Liu, L. P. Bian, B. S. Xu, Preparation and formation mechanism of smooth and uniform $\mathrm{Cu} 2 \mathrm{O}$ thin films by electrodeposition method, Surface \& Coatings Technology 216 (2013) 166-171.

[11] H. L. Xu, W. Z. Wang, W. Zhu, Shape evolution and size-controllable synthesis of $\mathrm{Cu}_{2} \mathrm{O}$ octahedra and their morphology-dependent photocatalytic properties, J. Phys. Chem. B 110 (2006) 13829-13834.

[12] A. S. Reddy, G. V. Rao, S. Uthanna, P. S. Reddy, Structural and optical studies on dc reactive magnetron sputtered $\mathrm{Cu}_{2} \mathrm{O}$ films, Mater. Lett. 60 (2006) 1617-1621.

[13] M. Pourbaix, Atlas of Electrochemical Equilibria in Aqueous Solutions, $2^{\text {nd }}$ English ed. National Association of Corrosion Engineers: Houston (1974) 384-392. 
[14] M. J. Siegfried, K. -S. Choi, Elucidating the effect of additives on the growth and stability of $\mathrm{Cu}_{2} \mathrm{O}$ surfaces via shape transformation of pre-grown crystals, J. Am. Chem. Soc. 128 (2006) 10356-10357.

[15] M. J. Siegfried, K. -S. Choi, Electrochemical crystallization of cuprous oxide with systematic shape evolution, Adv. Mater. 16 (2004) 1743-1746.

[16] L. Wang, M. Tao, Fabrication and characterization of p-n homojunctions in cuprous oxide by electrochemical deposition, Electrochem. Solid-State Lett. 10 (2007) H248-H250.

[17] M. Hara, T. Kondo, M. Komoda, S. Ikeda, K. Shinohara, A. Tanaka, J. N. Kondo, K. Domen, $\mathrm{Cu}_{2} \mathrm{O}$ as a photocatalyst for overall water splitting under visible light irradiation, Chem. Commun. (1998) 357-358. 